\title{
Creating bizarre false memories through imagination
}

\author{
AYANNA K. THOMAS and ELIZABETH F. LOFTUS \\ University of Washington, Seattle, Washington
}

\begin{abstract}
The present study explored memory for familiar or usual actions (e.g., flip the coin) and bizarre or unusual actions (e.g., sit on the dice). In Session l, action statements were presented to 210 participants, who had to either perform or imagine those actions. In Session 2, $24 \mathrm{~h}$ later, participants imagined performing various actions, some presented in the first session and others totally new. Finally, in Session 3 , 2 weeks later, participants were tested on their memory for the original actions. We found that as the number of imaginings increased in Session 2, so did the proportion of did responses to actions that were only imagined or not even presented. This pattern was present for both bizarre and familiar actions. These results demonstrate that bizarre actions may lose the item distinctiveness that is used to make accurate memory decisions after repeated imagination.
\end{abstract}

This research is about the power of imagination. Whereas others have investigated the power of imagination as a memory enhancing or mnemonic device, our interest is in the power of imagination to negatively affect memory. Over the past quarter century, researchers have begun to document some of the negative effects of imagination on memory. For example, Johnson and her colleagues demonstrated that thinking about (imagining) certain items (such as words) increased the frequency with which participants thought they had actually seen those words (Johnson, Raye, Wang, \& Taylor, 1979).

The power of imagination has also been shown in the domain of autobiographicalmemories. Garry, Manning, Loftus, and Sherman (1996) demonstrated that people show increased confidence ratings that a possibly fictitious childhood event occurred after imagining that event. Numerous other investigators similarly showed imagination inflation in this type of paradigm (Heaps \& Nash, 1999; Paddock et al., 1999). Although researchers have demonstrated that imagination can affect memory for our past, studies manipulating memory for childhood events suffer from a flaw. Researchers posit that imagination can lead to the creation of false childhood memories; however, instead of this negative effect, it is possible that imagination might only be triggering true memories about the past. In other words, imagination of a childhood event could trigger the recovery of that true memory, rather than implant a false memory, a possibility acknowledged by researchers who have used the paradigm.

This experiment was developed in partial fulfillment of the master of science degree at the University of Washington. Thanks are extended to John Bulevich and Yuichi Shoda for helpful commentary on previous versions of this manuscript. Correspondence should be addressed to A. K. Thomas, Box 1125, Psychology Department, Washington University, St. Louis, MO 63130 (e-mail: athomas@ artsci.wustl.edu).
To address this problem, Goff and Roediger (1998) developed a design that would allow investigators to know exactly what participants had and had not done. Participants in their study heard simple action statements (e.g., flip a coin) and sometimes also performed actions or imagined performing actions. In a later session, participants imagined performing a variety of actions, some that had been presented in the first session (performed, imagined, or heard) and others that had not been presented in the first session. In a final session, participants had to recognize whether an action had been presented at all in the first session and, if so, whether it had been actually performed, imagined, or merely heard. The main result was that increasing the number of imaginations during Session 2 led participants to remember carrying out actions during the first session when in fact they had not. Goff and Roediger found that after five imaginations, participants claimed $13 \%$ of the time that they had carried out actions in Session 1 that had not even been presented at all. Because Goff and Roediger designed a paradigm in which the experimenter knows precisely what participants did and did not initially do, their study demonstrates conclusively that imagination can lead to false memories. Specifically, when people imagine performing some action, they do sometimes later remember that they actually did that action.

\section{Bizarre False Memories}

Goff and Roediger(1998) provided strong evidence that imagination can lead to the creation of false memories. Their results did not, however, quiet the debate regarding the creation of false memories. Researchers continue to question whether more unusual events are susceptible to similar distortions in memory. Pezdek, Finger, and Hodge (1997) hypothesized that events will be suggestively implanted into memory on the basis of its plausibility. To test their hypothesis, they had Jewish and Catholic participants read two narratives, one describing a Jewish ritual and one 
describing a Catholic ritual. They found that 7 Catholics but 0 Jews remembered the Catholic false event, and 3 Jews but only 1 Catholic remembered the Jewish false event. Pezdek et al. concluded that more unusual information (Catholics attending a Jewish service) was less susceptible to memory distortions because people lacked the script-relevant information necessary to generate a false memory.

Others have discovered that rather unusual events can be implanted as false memories. With a strong suggestion from a family member, people have been led to believe that they had an overnight hospitalization (Hyman, Husband, \& Billings, 1995) or experienced a vicious animal attack (Porter, Yuille, \& Lehman, 1999). Hyman et al. found that after providing participants with descriptions of counterfactual childhood events, $20 \%$ of those participants agreed that the event did occur and provided a description of the event that included some of the introduced false information. In one study of the genre, conducted by Hyman and Pentland (1996), imagery was specifically used. Participants who engaged in guided imagery were more likely than controls to create a false event and to recover memories of previously unavailable true events.

Pezdek et al. (1997) argued that the events used in many false memory experiments are plausible to participants and thus more easily manipulated. They further contended that memory for a false event develops as a consequence of related information in memory. Therefore, if a script does not exist for a particular event, it would be significantly more difficult to create a false memory for that event. Because the events in their (Pezdek et al., 1997) experiments were more implausible or unusual, participants were far less likely to develop false memories. For example, if one has not attended (or watched) a Catholic or Jewish service, then one probably would be unaware of the script information associated with that event. Thus Pezdek et al. hypothesized that it is unlikely that recovered memories of childhood sexual abuse are false because of the lack of script-relevant knowledge.

In thinking about the application of these ideas to memories of child abuse, one must keep in mind that we cannot readily claim that such events are "implausible." There is no evidence to suggest that the event of childhood sexual abuse falls into this category of implausibility. Rather, in our society, we have been inundated with information regarding childhood physical abuse and sexual abuse in the last 15 years. We have been subjected to countless talk shows, made-for-TV-movies, and books on these issues. The script-relevant knowledge is now readily accessible to us, and thus the event is no longer implausible, at least according to the definition given by Pezdek et al. (1997). Rather, these events are unusual or bizarre to those who have not experienced them. In that case, information gathered from a study using bizarre events may aid in clarifying issues surrounding the implantation of false memories of childhood abuse.

\section{Bizarre True Memories}

Pezdek et al.'s (1997) findings would suggest that bizarre events would also be less susceptible to false memory creation. In addition, the literature that has examined memory for bizarre information suggests that people may remember unusual or bizarre information better, and thus develop fewer false memories, as compared with common or usual information. In fact, the memory literature is teeming with instances in which bizarre information is better remembered than common information when presented in mixed lists (McDaniel \& Einstein, 1986; McDaniel, Einstein, DeLosh, May, \& Brady, 1995). Although this effect disappears when unmixed lists are studies (only bizarre items or only common items), when bizarre items are studied along with common items, bizarre items are systematically remembered better. DeLosh and McDaniel (1996) argued that the disruption and enhancement of the encoding of serial order information is a key factor in this bizarre-imagery effect. They stated that order information is encoded for common or typical events but is disrupted for bizarre events because bizarre events require more attention to process. When common and bizarre actions are presented in mixed lists, order information for common items tends to be reduced because, in some cases, these items follow bizarre ones, which disrupt order encoding. Order information for bizarre items tends to improve because of the reverse set of circumstances. Further, bizarre items should be better remembered than common items because bizarre items benefit from the encoding of both serial-order information and extensive individual item information (Hunt \& McDaniel, 1993).

Item information has been shown to affect accurate retrieval in varied circumstances. Schacter, Israel, and Racine (1999) found that pictorial encoding of words allowed participants to use a general rule of thumb whereby they demanded access to detailed pictorial information in order to support a positive recognition decision. They referred to this reliance as the distinctiveness heuristic. As defined by Israel and Schacter (1997), the distinctiveness heuristic is a metamemorial process that participants may use at the time of retrieval to help decide whether a test item had been studied. Under conditions in which a participant believes that the retrieval of a studied item should be accompanied by distinctive recollections of its original occurrence, participants may require such distinctiverecollection before claiming to remember an item. If such distinctive information were absent, this would suggest to participants that the test item had not been studied.

One could posit that a similar heuristic may be at work with regard to bizarre action statements. For participants to support a positive performance decision, they may need to access information related to the encoding of the bizarre nature of the action. Chaiken, Liberman, and Eagly (1989) argued that when processing heuristically, people focus on a subset of available information that enables them to use simple inferential rules to formulate judgments. If a heuris- 
tic based on the bizarre nature of action statements is employed to endorse a positive recognition and performance decision, then bizarre actions will elicit far fewer false endorsements than will common actions.

\section{The Present Experiment}

In the present study, we used a paradigm similar to that developed by Goff and Roediger (1998) but we included a large set of bizarre actions as well as familiar ones. We put the idea of imagination leading to false memories to a stronger test by using bizarre information. On the basis of the literature regarding memory for distinctive or unusual information, we would predict that bizarre actions would be less susceptible to memory distortion than would more common ones. When individuals are asked whether they performed a bizarre action, item distinctiveness, and/or serial order may be used to make this decision. Further, because bizarre actions generally exhibit better "true" memory than do familiar actions, we expected a similar pattern to unveil itself when false memories were examined. Finally, we were interested in whether the examination of memory for bizarre or unusual actions can aid in the understanding of uncommon childhood false memories.

In addition to further investigating the differences between common and uncommon actions, we were interested in how imagination changes the quality of a memory. $\mathrm{Nu}-$ merous researchers have demonstrated that imagination can lead people to believe that something happened when it never actually did, but how certain are people of these memories? Do they actually have a conscious recollection of doing something rather bizarre? To test this question, we asked participants to provide a remember/know judgment. A remember judgment was reserved for memories in which participants had an explicit recollection of the event. Know judgments refer to a feeling of knowing about the occurrence of the event (Gardiner, Ramponi, \& Richardson-Klavehn, 1998; Rajaram, 1993; Tulving, 1985).

\section{METHOD}

\section{Participants}

The participants were 238 University of Washington undergraduates. Only 210 participants completed all three sessions. They received extra credit toward an introductory psychology course. Participants were tested in groups ranging from 6 to 8 per group.

\footnotetext{
Materials and Procedure

We generated 54 critical action statements. Of those, 24 were taken from Goff and Roediger's (1998) experiment. We developed 30 additional action statements, 27 of which comprised our bizarre action statements, and 3 additional familiar action statements were added to the Goff and Roediger actions. The bizarre and familiar action statements used in this experiment are listed in the Appendix. We defined a bizarre action statement as a statement that used familiar objects in a bizarre manner (i.e., kiss the magnifying glass). Similarly, a familiar action statement was defined as a statement that used familiar objects in a familiar manner (i. e., flip the coin). To determine whether an action statement was familiar or bizarre, a separate group of 74 participants rated all of the action statements on an 8-point
}

Likert scale $(1=$ extremely familiar $; 8=$ extremely bizarre $)$. The mean rating for actions designated as familiar was 2.4 ; the mean rating for actions designated as bizarre was 6.7. Action statements were divided equally, so that all participants were presented with the same number of familiar and bizarre action statements. The test materials (given 2 weeks later) included all 54 of the critical actions.

During Session 1, participants were randomly assigned to one of nine counterbalancing conditions to control for the possibility of presentation-order effects and to ensure that each action statement was performed, imagined, or not presented during the first session, and imagined zero, one, or five times during the second session. Half of the actions presented were familiar and half were bizarre. Bizarre and familiar actions were presented in a random order to participants to mimic the presentation style used by McDaniel et al. (1995). For the second session, if an action was imagined more than once, the occasions were spaced with a lag of at least three actions between presentations. As in the first session, half of the actions presented in Session 2 were familiar and half were bizarre, and bizarre and familiar actions were presented randomly. Participants run together during Session 1 were run together for Sessions 2 and 3. Participants tested at the same time were presented with the same order of action statements in the first and second sessions. Thus, participants in a group performed and imagined performing the same action statements.

Session 1: Encoding of events. After signing a consent form, participants sat at a table that contained various items that would be used for action or imagination. There were 2 participants at each table. Objects necessary to perform all 54 critical actions were set out for each participant. A dividing partition was erected between the 2 participants at each table. Participants were informed that they would be asked either to perform or to imagine performing simple actions using the materials in front of them. We were concerned that the presence of all of the items would potentially inflate did and imagined responses. However, even if this were the case, this increase would elevate the responses across all three (zero, one, and five imaginings) conditions of Session 2 in an equivalent way, because objects were presented for all actions. Therefore, the difference among the three conditions would still give us an accurate picture of the pattern of the effects. If all responses were elevated because of the presence of the items during Session 1, the pattern of the effect (across repeated imagination) should not be significantly affected.

Before action statements were read, the experimenter acquainted the participants with the objects before them. Participants were shown each object individually and were aware of each object's location on the table. Further, they were instructed not to watch what others were doing. Of the 54 critical action statements generated, 36 were either performed or imagined by a participant during Session 1 . Thus, critical action statements were divided in such a way that 18 actions were performed, 18 actions were imagined, and 18 actions were not presented at all during Session 1.

Participants were informed that they would hear action statements that involved simple requests. For some statements, they would be asked to do the actions and for others they would imagine the actions. They were told to use the materials at the table in front of them when performing actions. The 36 action statements (18 performed and 18 imagined) were read aloud by the experimenter. Participants were given $15 \mathrm{sec}$ to either imagine or perform the action. Participants continued to perform or imagine the action for the full 15 -sec interval. After the 36 actions statements had been presented, participants were reminded of the second session and then dismissed.

Session 2: Imagining. Participants returned $24 \mathrm{~h}$ later for the second session. In this session all action statements presented were imagined. Seven seconds were given for each imagination. Of the 54 critical action statements, 18 were not imagined at all, 18 were imagined one time, and 18 were imagined five times. Further, of the 18 performed in Session 1, 6 were not imagined, 6 were imagined one 
time, and 6 were imagined five times. The same was true for actions imagined in Session 1 and for actions not presented in Session 1.

Participants imagined a total of 108 actions. To help ensure that participants actually performed the imagination, after each action statement was imagined, participants had to rate the vividness of the imagination $(1=$ not vivid $; 2=$ slightly vivid $; 3=$ somewhat vivid $; 4=$ very vivid; $5=$ extremely vivid). At the end of this session, participants were reminded about the third session and dismissed.

Session 3: Testing. Two weeks later, participants returned and were given a recognition test, a source monitoring test, and a remember/ know test. All of the 54 critical actions were presented in a fixed random order. Participants were given explicit instructions to answer the recognition and source monitoring questions solely on the basis of what they remembered from Session 1. Participants first answered the question, "Was the action presented during Session 1 [performed or imagined]?" If a participant responded "yes," he/she made a source judgment as to whether the action had been performed or imagined. After participants completed the source monitoring task, they were asked to indicate whether they remembered an action or whether they had a feeling of knowing. Participants were instructed to make these remember/know judgments on the basis of their memory for the actual presentation. Further, they were instructed that a remember judgment should be made for items for which they had a vivid memory of the actual presentation. That is, if they were able to bring back to mind some recollection of what occurred at the time of encoding, a remember judgment should have been given. They were instructed to reserve know judgments for items that they were sure had been presented but for which they lacked the feeling of remembering the actual occurrence of the presentation (Gardiner, 1988; Rajaram, 1993; Tulving, 1985).

\section{RESULTS}

Recall that participantsfirst made a recognition judgment ("Was the action presented in Session 1?") followed by a source monitoring judgment ("If yes, was it performed or imagined?"). We examined whether intervening imaginations influenced either recognition or source monitoring, and also whether repeated imagination of an action in Session 2 would change the quality of memory.

For ease of exposition, we first present the data regarding repeated imagination on source and quality judgments, and then the findings regarding recognition. To preview our findings, we obtained evidence for "imagination inflation." As participants imagined various actions repeatedly, the likelihood of giving a did response to actions that had not been performed also increased. Imagination inflation occurred for both familiar and bizarre actions that had not been performed in the encoding session; however, a stronger imagination inflation effect was found for familiar actions than for bizarre actions. We found that as the number of imaginings increased in Session 2, the proportion of remember responses also increased for actions erroneously identified as having been performed. Finally, we found that as the number of imaginations increased, the recognition accuracy decreased for actions performed and imagined in Session 1 . In addition, bizarre actions were better recognized than familiar ones. We now elaborate on these findings.

\section{Source Monitoring and Imagination Inflation}

First, we examined the mean proportion of $\mathrm{did}$ responses to novel actions that were never even presented during the first session. These false alarms were a function of the number of imaginings in the Session 2. The first section of Table 1 illustrates that with no intervening imaginations, participants gave false did responses only $4.0 \%$ of the time for familiar actions. However, after five imaginings, false $\mathrm{did}$ responses rose to $24.0 \%$. Notice also that imagination inflation occurred for bizarre actions as well: False did responses increased from $4.0 \%$ after no imaginations to $14.0 \%$ after five imaginations. Thus, we found that despite the fact that the action statement (e.g., kiss the magnifying glass) had not even been heard during the initial encoding session, a sizable minority of participants claimed they had actually performed that action after imagination; however, the inflation observed to bizarre actions was not as great as that observed to familiar actions.

A 3 (number of imaginings: $0,1,5) \times 2$ (type of action: familiar, bizarre) within-participants analysis of variance (ANOVA) was performed on false did responses to actions not performed or imagined in Session 1. Unless otherwise stated, all statistical tests reported have a $p$ value less than .05. As the number of imaginings increased, the proportion of erroneous $d i d$ responses also increased. This main effect for number of imaginings was significant $\left[F(2,418)=40.57, M S_{\mathrm{e}}=0.06\right]$.

Although the false $d i d$ responses to familiar and bizarre actions both increased after repeated imagination, the in-

Table 1

Mean Source Monitoring and Remember/Know Judgments for Actions Not Presented, Imagined, and Performed in Session 1

\begin{tabular}{|c|c|c|c|c|}
\hline \multirow[b]{2}{*}{ Type of Action } & \multicolumn{2}{|c|}{ Familiar } & \multicolumn{2}{|c|}{ Bizarre } \\
\hline & $M$ & $S D$ & $M$ & $S D$ \\
\hline \multicolumn{5}{|c|}{ Not presented in Session 1/said "did" } \\
\hline Imagined 0 & 0.04 & 0.17 & 0.04 & 0.17 \\
\hline Remember & 0.01 & & 0.01 & \\
\hline Know & 0.03 & & 0.03 & \\
\hline Imagined 1 & 0.20 & 0.35 & 0.10 & 0.22 \\
\hline Remember & 0.12 & & 0.05 & \\
\hline Know & 0.08 & & 0.05 & \\
\hline Imagined 5 & 0.24 & 0.34 & 0.14 & 0.27 \\
\hline Remember & 0.14 & & 0.08 & \\
\hline Know & 0.10 & & 0.06 & \\
\hline \multicolumn{5}{|c|}{ Imagined in Session 1/said "did" } \\
\hline Imagined 0 & 0.03 & 0.16 & 0.02 & 0.12 \\
\hline Remember & 0.02 & & 0.01 & \\
\hline Know & 0.01 & & 0.01 & \\
\hline Imagined 1 & 0.19 & 0.35 & 0.09 & 0.21 \\
\hline Remember & 0.16 & & 0.05 & \\
\hline Know & 0.03 & & 0.04 & \\
\hline Imagined 5 & 0.23 & 0.34 & 0.14 & 0.27 \\
\hline Remember & 0.19 & & 0.10 & \\
\hline Know & 0.04 & & 0.04 & \\
\hline \multicolumn{5}{|c|}{ Performed in Session 1/said "did" } \\
\hline Imagined 0 & 0.78 & 0.28 & 0.85 & 0.28 \\
\hline Remember & 0.60 & & 0.68 & \\
\hline Know & 0.40 & & 0.32 & \\
\hline Imagined 1 & 0.84 & 0.26 & 0.92 & 0.17 \\
\hline Remember & 0.68 & & 0.75 & \\
\hline Know & 0.32 & & 0.25 & \\
\hline Imagined 5 & 0.85 & 0.23 & 0.93 & 0.17 \\
\hline Remember & 0.66 & & 0.75 & \\
\hline Know & 0.34 & & 0.25 & \\
\hline
\end{tabular}


crease was more pronounced for familiar actions than for bizarre actions. After five imaginings, participants erroneously claimed they performed a familiar new action $24.0 \%$ of the time. This is almost two times greater a false alarm rate than that obtained for bizarre actions. Statistical analyses revealed that this type of action difference was significant $\left[F(1,209)=17.82, M S_{\mathrm{e}}=0.08\right]$. In addition, the interaction between type of action and number of imaginings was significant $\left[F(2,418)=5.79, M S_{\mathrm{e}}=0.05\right]$.

We also examined the increase in the proportion of false did responses to actions that were imagined (although never performed) in Session 1. The second section of Table 1 reveals the proportion of times participants erroneously claimed that they had performed actions that were only imagined in Session 1. As the number of imaginings increased from 0 to 5, the proportion of erroneous did responses to actions originally imagined increased from $2.5 \%$ to $18.5 \%$ (averaging responses to familiar and bizarre actions). The effect of number of imaginings on false did responses for actions imagined in Session 1 was reliable $\left[F(2,418)=52.19, M S_{\mathrm{e}}=0.05\right]$. Thus, once again, the additional imaginings in Session 2 increased the incidence of false $d i d$ responses.

In addition, when type of action was compared, we found that participants were more susceptible to errors in memory when familiar as opposed to bizarre actions were tested $\left[F(1,209)=19.75, M S_{\mathrm{e}}=0.07\right]$. These results are consistent with those found when responses to actions not presented in Session 1 were analyzed. That is, participants were more likely to claim that an imagined familiar action was performed in Session 1 as opposed to an imagined bizarre action. This is not to say that bizarre actions were not susceptible to the imagination inflation effect. As Table 1 illustrates, at five imaginings, participants claimed that an imagined bizarre action was performed $14.0 \%$ of the time. Finally, the interaction between action type and number of imaginings was significant $[F(1,209)=4.70$, $\left.M S_{\mathrm{e}}=0.05\right]$.

The pattern of false $d i d$ responses is strikingly similar between actions never presented in Session 1 and actions imagined in Session 1. A 3 (number of imaginings: 0, 1,5) $\times 2$ (type of presentation: not presented, imagined) $\times 2$ (type of action: familiar, bizarre) ANOVA was performed to compare the false did responses with imagined and not presented actions. We did not find a significant difference between the false $d i d$ responses to imagined as opposed to not presented actions $(F<1)$. Further, type of Session 1 activity did not significantly interact with number of imaginings $(F<1)$, nor did it interact with type of action $(F<1)$. However, as expected, as the number of imaginings increased, so did the proportion of false did responses $\left[F(2,418)=47.99, M S_{\mathrm{e}}=0.12\right]$. Also, as expected, a significant difference between type of action was presented $\left[F(1,209)=19.20, M S_{\mathrm{e}}=0.16\right]$. Finally, the interaction between type of action and number of imaginings was significant $\left[F(2,418)=5.43, M S_{\mathrm{e}}=0.11\right]$.

We also examined how imagination affected memory for performed actions. The last section of Table 1 demon- strates that after repeated imagination, participants were significantly more likely to correctly remember performing an action $\left[F(2,418)=14.08, M S_{\mathrm{e}}=0.05\right]$. Thus, repeated imagination had a beneficial effect on actions that were performed in Session 1. We also found that bizarre actions elicited more accurate $d i d$ responses as compared with familiar actions $\left[F(1,209)=38.34, M S_{\mathrm{e}}=0.05\right]$. These results are consistent with the theory that bizarre information is remembered better than familiar information when presented in mixed lists. Finally, the interaction between type of action and number of imaginings was not significant $(F<1)$.

\section{Remember/Know Judgments as a Measure of False Memory Quality}

We also explored whether the quality of the memory changes with repeated imagination. To assess memory quality, we asked participants to provide a remember/ know judgment after they had completed the recognition and source monitoring tests for a particular action statement. Participants made a remember/know judgment only if they indicated that they had performed the action during Session 1. Remember/know judgments were examined by response of the participants, by number of imaginings in Session 2, and by type of action.

Not presented but said performed. Table 1 illustrates that as the number of imaginings increased, the proportion of remember responses to actions not presented in Session 1, but remembered as having been performed, also increased. At zero imaginings, participants gave these memory illusions remember responses $0.01 \%$ of the time for familiar actions; however, after five imaginings remember responses increased to $14.0 \%$. Repeated imagination also increased remember judgments for bizarre actions not presented in Session 1, but falsely remembered as having been performed.

A 3 (number of imaginings: $0,1,5) \times 2$ (type of actions: familiar, bizarre) ANOVA was performed on the remember responses made to not-presented actions falsely remembered as having been performed. It should be noted that because items were selected on the basis of source monitoring judgments, not all participants contributed to the remember data. The analysis performed was done so for actions falsely remembered as having been performed. Because of this selection, the degrees of freedom do not correspond to the number of participants in this experiment. As expected, we found a significant main effect for number of imaginings $\left[F(2,94)=6.51, M S_{\mathrm{e}}=0.24\right]$. However, there was no significant main effect for type of action $(F<1)$ nor any interaction between number of imaginings and type of action was not significant $(F<1)$.

A similar analysis was performed on the know responses for actions not presented but falsely reported as having been performed. We found no effect for number of imaginings and no effect for action type $(F<1)$. That is, know judgments did not significantly increase with repeated imagination, and familiar and bizarre actions were equally as likely to elicit know responses. 
Imagined but said performed. A similar remember/ know analysis was performed for responses made to actions imagined in Session 1, but erroneously remembered as having been performed. As with not-presented actions, we found that as the number of imaginings increased, so did the proportion of remember responses. As Table 1 illustrates, at zero imaginings, remember responses were given to familiar imagined actions erroneously reported as performed $2.0 \%$ of the time. After five imaginings, the proportion of remember responses to these actions increased to $19 \%$. A similar pattern of remember responses was obtained for bizarre actions.

A 3 (number of imaginings: $0,1,5) \times 2$ (type of actions: familiar, bizarre) ANOVA was performed on the remember and know responses made to imagined actions reported as performed. As expected, a significant main effect for number of imaginings was obtained $[F(2,110)=$ $\left.2.96, M S_{\mathrm{e}}=0.21\right]$. In addition, similar to the results for the remember responses to not-presented actions, we found no type of action difference for remember responses given to imagined actions reported as having been performed $(F<1)$. And again, the interaction between number of imaginings and type of action was not significant when remember judgments were used as the dependent measure $(F<1)$.

As with false alarms to not-presented actions, we examined the know responses to false alarms to imagined actions and found no effect of number of imaginings $(F<1)$ or effect of type of action $(F<1)$. Neither of these variables affected know responses, whereas number of imaginings did have a significant effect on remember responses.

Performed and said performed. As with imagined and not-presented actions falsely remembered as performed, participants provided remember/know judgments for actions correctly remembered as having been performed. These data are illustrated in the last section of Table 1. As can be seen in Table 1, participants most often gave remember responses to actions correctly reported as performed. In addition, when remember responses across number of imaginings were analyzed, no significant difference was found $(F<1)$. That is, repeated imagination in the second session did not affect the remember responses given to performed action statements. In addition, no type of action difference was found in the remember responses $(F<1)$, and the interaction between number of imaginings and type of action was not significant $(F<1)$. Participants were equally likely to give remember responses to familiar actions as to bizarre actions.

\section{Recognition}

Recall that for each action, participants had to first say whether the action had been presented at all during Session 1 . We refer to this as our recognitiontest. We were interested in how the intervening imagination session would affect participants' ability to remember whether an action had been presented at all during Session 1. Our analysis of these responses focuses on hits and false alarms. Recognition was scored as a correct "hit" if the action statement had been presented to participants during Session 1 (as either performed or imagined), and participants responded "yes" that it had been presented. Recognition was scored as an erroneous "false alarm" if the statement had not been presented during Session 1, but participants responded "yes."

Table 2 illustrates that as the number of imaginings increased, recognition accuracy, as measured by $d^{\prime}$, decreased. A 3 (number of imaginings: 0,1 , or 5$) \times 2$ (presentation: performed, imagined) $\times 2$ (type of action: familiar, bizarre) within-participants ANOVA was performed on recognition accuracy. A main effect for number of imaginings was found $\left[F(2,418)=186.82, M S_{\mathrm{e}}=8.76\right]$. As expected, we found that as the number of imaginings increased (for actions imagined in Session 1 and collapsed across type of action) from 0 to 1 in Session 2, $d^{\prime}$ scores decreased $[t(209)=7.75, S E=0.15]$. Similarly, we found that as the number of imaginings increased from one to five, recognition performance again significantly declined $[t(209)=17.47, S E=0.16]$. In addition, we found that participants were more accurate at recognizing whether a bizarre action had been presented as opposed to a familiar action. This difference between types of action was significant $\left[F(1,209)=21.93, M S_{\mathrm{e}}=6.30\right]$. Finally, participants were more accurate at recognizing whether a performed action had been presented during Session 1 as opposed to an imagined action $\left[F(1,209)=78.66, M S_{\mathrm{e}}=4.01\right]$. These findings are consistent with those obtained by Cohen (1984) and others (e.g., Engelkamp \& Zimmer, 1984) who have demonstrated that memory for performed actions is better than memory for actions that are just heard.

Also one should take notice of the significant interaction between number of imaginings and type of action $\left[F(2,418)=36.30, M S_{\mathrm{e}}=6.10\right]$. This crossover interaction demonstrated that at zero imaginings, participants were

Table 2

Mean Recognition Accuracy $\left(d^{\prime}\right)$ (Was the Action Presented During Session 1?)

Number of Imaginings

\begin{tabular}{lcccccc} 
& \multicolumn{6}{c}{ Number of Imaginings } \\
\cline { 2 - 7 }$\quad M$ & $S D$ & $M$ & $S D$ & $M$ & $S D$ \\
\hline Measure & & & & & & \\
$\quad$ Pamiliar & & & & & & \\
$\quad$ Hits & 0.89 & 0.21 & 0.95 & 0.12 & 0.80 & 0.33 \\
$\quad$ False alarms & 0.11 & 0.01 & 0.37 & 0.33 & 0.61 & 0.32 \\
$\quad d^{\prime}$ & 3.92 & 1.75 & 3.36 & 2.21 & 1.08 & 2.72 \\
$\quad$ Bizarre & & & & & & \\
$\quad$ Hits & 0.93 & 0.16 & 0.97 & 0.08 & 0.83 & 0.31 \\
$\quad$ False alarms & 0.03 & 0.05 & 0.39 & 0.31 & 0.71 & 0.32 \\
$\quad d^{\prime}$ & 5.30 & 1.32 & 3.31 & 2.14 & 0.64 & 2.36 \\
$\quad$ Imagined & & & & & & \\
$\quad$ Familiar & & & & & & \\
$\quad$ Hits & 0.55 & 0.36 & 0.77 & 0.29 & 0.85 & 0.24 \\
$\quad$ False alarms & 0.11 & 0.01 & 0.37 & 0.33 & 0.61 & 0.32 \\
$\quad d^{\prime}$ & 1.97 & 2.44 & 3.83 & 2.17 & 2.39 & 2.53 \\
$\quad$ Bizarre & & & & & & \\
$\quad$ Hits & 0.67 & 0.35 & 0.87 & 0.22 & 0.91 & 0.19 \\
$\quad$ False alarms & 0.03 & 0.05 & 0.39 & 0.31 & 0.71 & 0.32 \\
$\quad d^{\prime}$ & 2.73 & 2.29 & 1.35 & 2.22 & 1.08 & 1.94 \\
\hline
\end{tabular}


more accurate when asked about the presentation of bizarre actions as opposed to familiar actions. However, as the number of imaginings increased, the benefit that bizarre actions had (with regard to "true" memories) disappeared. At five imaginings, familiar actions were more accurately remembered than bizarre ones. However, the difference between familiar and bizarre actions was not significant at one or five imaginings $(t<1)$.

A similar interaction was found between number of imaginings and type of presentation $\left[F(1,209)=15.97, M S_{\mathrm{e}}=\right.$ 1.16]. At zero imaginings, participants were more accurate in recognizing actions performed in Session 1 as opposed to actions imagined in Session 1. However, after five imaginings, that advantage disappeared, and accuracy did not differ between performed and imagined actions $(t<1)$.

\section{DISCUSSION}

Probably the most dramatic result to emerge from this study is the finding that after repeated imagination, participants not only reported that never presented bizarre actions were presented during Session 1, but also claimed that they had performed these actions. After five imaginations, people claimed that they had performed new bizarre actions $14.0 \%$ of the time. Although the increase in false $d i d$ responses to bizarre actions was significant, it was less than the increase observed for familiar actions. After five imaginings, people claimed that a familiar action never presented during Session 1 had been performed $24.0 \%$ of the time.

False memories of performance were also seen in other aspects of our data. We examined whether we could get people to think that they had performed familiar and bizarre actions that had been merely imagined in Session 1. We found that as the number of imaginings increased, the proportion of erroneous did responses for both familiar and bizarre actions imagined in Session 1 also increased. At zero imaginings, participants claimed that bizarre imagined actions had been performed $2.0 \%$ of the time. However, after five imaginings, the percentage rose to 14.0. A similar pattern was present for familiar imagined actions. Again, we have demonstrated that after repeated imaginings, people can erroneously come to believe that they have performed a bizarre action.

\section{Why Does Imagination Lead to False Memories?}

In this study, we found that repeated imagination led people to falsely claim that familiar and bizarre actions had been performed. One possible explanation for this effect is that repeated imagination increased participants' familiarity with the statement, leading them to make a did response because they mistook that familiarity for a memory of actual performance (Jacoby \& Whitehouse, 1989). A second explanation can be understood within the context of a source monitoring framework (Johnson, Hashtroudi, \& Lindsay, 1993). Specifically, perhaps repeated imagination led participants to develop or construct additional contextual features that could cause a later misattribution of performance. When participants repeatedly imagined an action statement, it is possible that the cues associated with those imaginations became confused with cues associated with actual performance, hindering participants' ability to accurately distinguish between imagination and performance. It is possible that repeated imagination led participants to develop false contextual cues to support their false memories of performance.

\section{False Memories for Bizarre Actions}

It is obvious that within this paradigm, false memories of performance can be created for more unusual or bizarre events. However, as predicted, participants were less likely to falsely remember performing a bizarre action as opposed to a familiar action. These results are consistent with the established findings that people have better memory for unusual information when unusual and common information is presented randomly within the context of the same list (McDaniel et al., 1995). Nonetheless, after repeated imagination, participants do falsely remember performing bizarre actions. These results provide support that bizarre or unusual events are subject to errors in memory, albeit to a much smaller extent.

As Pezdek et al. (1997) argued, script-relevant information may be a precursor to the creation of false memories; however, it is possible that repetition of information (through repeated imagination) may lead to the development of script-relevant information that may, in turn, affect the creation of false memories. Although this paradigm does not directly correspond to that used by Pezdek et al., it does provide support that, at least for bizarre information, repetition of the false memory creation procedure (in this case, imagination) may lead to the development of information used to make erroneous memory judgments.

On the other hand, script-relevant information may not be a factor in this false memory paradigm. The bizarre actions used in this experiment were far different from the unusual events used in Pezdek et al. (1997) experiment. It is possible that script-relevant information may be a necessary component of false memory creation for unusual and complex autobiographical events, but not for simple actions. This component of false memory creation needs to be examined in future experiments.

\section{Recognition and Repeated Imagination}

Although recognition hit rates increased with repeated imagination, false alarm rates increased even more; thus overall recognition accuracy decreased with repeated imagination. The percent of "false presented" responses increased from $6.0 \%$ at zero imaginings to $69.0 \%$ at five imaginings (averaging across familiar and bizarre false alarm responses). That is, after five imaginings in Session 2, participants erroneously claimed that an action only presented in Session 2 (24 h later) had been presented in Session 1.

Although not as impressive a result as erroneously claiming that a novel action had been performed, temporal er- 
rors in source monitoring have important practical consequences. When witnesses were interviewed after the bombing of the Alfred P. Murrah Federal Building in Oklahoma City in 1995, several reports of a second participant in this attack surfaced. A witness at the truck rental agency claimed that a second man (later known as John Doe 2) rented the truck with Timothy McVeigh (who was later tried and convicted of this bombing). The witness even produced a composite sketch of John Doe 2. However, when the matter was investigated further, police officials determined that the witness had been incorrect. John Doe 2 did exist, but had accompanied another truck renter to the agency on a different day. The witness's obvious temporal source monitoring error led to an unnecessary manhunt throughout the area.

Also of interest is the effect of repeated imagination on recognition memory for bizarre actions. Our recognition results support previous findings that show that bizarre items are better remembered than familiar ones when presented in mixed lists. However, after five imaginings, this bizarre-imagery effect disappeared. Recognition accuracy was slightly greater for familiar actions than for bizarre ones. One possible explanation for these results is that the distinctive aspects of bizarre actions may become less salient with repeated imagination. Thus, item information no longer provides the benefit that it once did. A second possible explanation is that after repeated imagination during the second session serial-order information was disrupted for bizarre actions, again leading to a decline in recognition accuracy.

\section{Other Findings}

Finally, we found that imagination seems to affect the quality of a memory as assessed through an increase in the proportion of remember responses to action statements that were falsely remembered as having been performed. Remember responses associated with false memories of performance indicate that these false memories may have developed some episodic content (Roediger \& McDermott, 1995). It is possible that this false episodic content develops because of the reconstructive nature of memory. Participants may have drawn upon the episodic content of actions actually performed in this experiment and misattributed that content to actions only imagined or not presented.

Hyman, Gilstrap, Decker, and Wilkinson (1998) found that when participants formed images and answered questions on the basis of the images, for an event previously given a know response, these participants later reevaluated their remember/know judgment and moved toward the middle of the remember/know scale. The act of imagination in our study could be producing a similar effect.

\section{Applications and Future Directions}

The present study provides additional insight into the creation of false memories. Specifically, we have demonstrated that repeated imagination can affect people's ability to later determine whether an event actually took place.
Additionally, the robust bizarre-imagery effect was eliminated after repeated imagination. And perhaps most importantly, bizarre actions were susceptible to false memory creation.

This study has provided additional information that can be used to clarify the debate over the creation of false memories for unusual events, such as abuse. Future studies should examine the underlying mechanisms of the creation of false memories. The data from this study suggest that contextual cues, such as sensory information, may be an important factor in false memory creation. This question may be further addressed by having participants complete a Memory Characteristics Questionnaire (Johnson, Foley, Suengas, \& Raye, 1988) for actions they correctly and incorrectly remember as performed. It is plausible that imagination influences the visual detail (or other sensory component) associated with a false memory, and the report of visual detail may approach that given to actions that were correctly remembered as having been performed as the number of imaginings increases. Finally, although researchers have speculated, we are not certain whether script-relevant information is necessary for false memory creation, and we are unsure whether script-relevant information can be generated through the repetition of a specific technique. Research directed at answering these questions will further aid in our understanding of false memory creation.

\section{REFERENCES}

Chaiken, S., Liberman, A., \& Eagly, A. H. (1989). Heuristic and systematic information processing within and beyond the persuasion context. In J. S. Uleman \& J. A. Bargh (Eds.), Unintended thought (pp. 212252). New York: Guilford.

Cohen, R. L. (1984). Individual differences in event memory: A case for nonstrategic factors. Memory \& Cognition, 12, 633-641.

DeLosh, E. L., \& McDAniel, M. A. (1996). The role of order information in free recall: Application of the word-frequency effect. Journal of Experimental Psychology: Learning, Memory, \& Cognition, 22, 1136-1146.

ENGELKAMP J., \& Zimmer, H. D. (1984). Motor programme information as a separable memory unit. Psychological Research, 46, 283-289.

GARDINER, J. M. (1988). Functional aspects of recollective experiences. Memory \& Cognition, 16, 309-313.

Gardiner, J. M., Ramponi, C., \& Richardson-Klavehn, A. (1998). Experiences of remembering, knowing, and guessing. Consciousness \& Cognition, 7, 1-26.

Garry, M., Manning, C. G., Loftus, E. F., \& Sherman, S. J. (1996). Imagination inflation: Imagining a childhood event inflates confidence that it occurred. Psychonomic Bulletin \& Review, 3, 208-214.

GoFf, L. M., \& RoEdiger, H. L., III (1998). Imagination inflation for action events: Repeated imaginings lead to illusory recollections. Memory \& Cognition, 26, 20-33.

HEAPS, C., \& NASH, M. (1999). Individual differences in imagination inflation. Psychonomic Bulletin \& Review, 6, 313-318.

Hunt, R. R, \& McDaniel, M. A. (1993). The enigma of organization and distinctiveness. Journal of Memory \& Language, 32, 432-445.

Hyman, I. E., JR., Gilst Rap, L. L., Decker, K., \& Wilkinson, C. (1998). Manipulating remember and know judgments of autobiographical memories: An investigation of false memory creation. Applied Cognitive Psychology, 12, 371-386.

Hyman, I. E., JR., Husband, T. H., \& Billings, J. F. (1995). False memories of childhood experiences. Applied Cognitive Psychology, 9, 181197. 
Hyman, I. E. \& Pentland, J. (1996). The role of mental imagery in the creation of false childhood memories. Journal of Memory \& Language, 35, 101-117.

IsRAel, L., \& Schacter, D. L. (1997). Pictorial encoding reduces false recognition of semantic associates. Psychonomic Bulletin \& Review, 4, 577-581.

JACOBY, L. L., \& Whitehouse, K. (1989). An illusion of memory: False recognition influenced by unconscious perception. Journal of Experimental Psychology: General, 118, 126-135.

Johnson, M. K., Foley, M. A., Suengas, A. G., \& Raye, C. L. (1988). Phenomenal characteristics of memories for perceived and imagined autobiographical events. Journal of Experimental Psychology: General, 117, 371-376.

Johnson, M. K., Hashtroudi, S., \& LindSay, D. S. (1993). Source monitoring. Psychological Bulletin, 114, 3-28.

Johnson, M. K., RaYe, C. L., WANG, A. Y., \& TaYlor, T. H. (1979). Fact and fantasy: The roles of accuracy and variability in confusing imaginations with perceptual experiences. Journal of Experimental Psychology: Human Learning \& Memory, 5, 229-240.

McDaniel, M. A., \& Einstein, G. O. (1986). Bizarre imagery as an effective memory aid: The importance of distinctiveness. Journal of Experimental Psychology: Learning, Memory, \& Cognition, 12, 54-65.

McDaniel, M. A., Einstein, G. O., DeLosh, E. L., May, C. P., \& BRADY, P. (1995). The bizarreness effect: It's not surprising, it's complex. Journal of Experimental Psychology: Learning, Memory, \& Cognition, 21, 422-435.

Paddock, J. R., Noel, M., Terronova, S., Eber, H. W., Manning, C. G., \& LoFTUS, E. F. (1999). Imagination inflation and the perils of guided visualization. Journal of Psychology, 133, 581-595.

Pezdek, K., Finger, K., \& Hodge, D. (1997). Planting false childhood memories: The role of event plausibility. Psychological Science, $\mathbf{8}$, 437-441.

Porter, S., Yuille, J. C., \& Lehman, D. R. (1999). The nature of real, implanted, and fabricated memories for emotional childhood events: Implications for the recovered memory debate. Law \& Human Behavior, 23, 517-537.

RAJARAM, S. (1993). Remembering and knowing: Two means of access to the personal past. Memory \& Cognition, 21, 89-102.

Roediger, H. L., III, \& McDermott, K. B. (1995). Creating false memories: Remembering words not presented in lists. Journal of Experimental Psychology: Learning, Memory, \& Cognition, 21, 803-814.

Schacter, D. L., Israel, L., \& Racine, C. (1999). Suppressing false recognition in younger and older adults: The distinctiveness heuristic. Journal of Memory \& Language, 40, 1-24.

Tulving, E. (1985). Memory and consciousness. Canadian Psychologist, 26, 1-12.

\section{APPENDIX \\ 54 Critical Actions}

Familiar items: Sign your name on the paper with the pen, stir the water with the spoon, bounce the ball on the floor, put the top on the jar, sharpen the pencil with the pencil sharpener, cut the deck of cards, look through the magnifying glass, stick the straight pin in the thread, light the lighter, roll the pen on the table, fasten the safety pin, smell the flower, fold the piece of paper, cut the piece of thread with the scissors, tie a loose knot in the shoelace, draw a circle on the paper with the pen, break the toothpick, pick up the chalk, flip the coin, stretch the rubber band, remove a tissue from the box, roll the dice on the table, cut a piece of twine off of the spool with the scissors, measure your index finger with the ruler, sip the water, tear the paper, open the book.

Bizarre items: Tap the flower on your forehead, balance the ruler on your head, step into the plastic bag, balance the spoon on your nose, sit on the dice, place the nail clipper in the glass of water, print WORD with nail polish on the napkin, place the lighter in the tissue box, stab the Silly Putty with the pencil, sharpen the shoelace with the pencil sharpener, put the hair clip around the ball, place the hair clip on your shoe, use the scissors to try to cut the toothpick, crush the pill with the bottle, rub the Q-tip on your eyebrow, wrap the eraser in the napkin, put the empty cup over your ear, stick the straight pin in the doll, use the nail clipper to cut the napkin, put the basket over your eyes, bore a hole in the candle with the safety pin, place the bowl on your head, kiss the magnifying glass, tie the shoe lace around your leg, crush the paper and put it into the glass of water, rub lotion on the chair, stick the needle in the carpet.

(Manuscript received August 17, 2000; revision accepted for publication January 16, 2002.) 